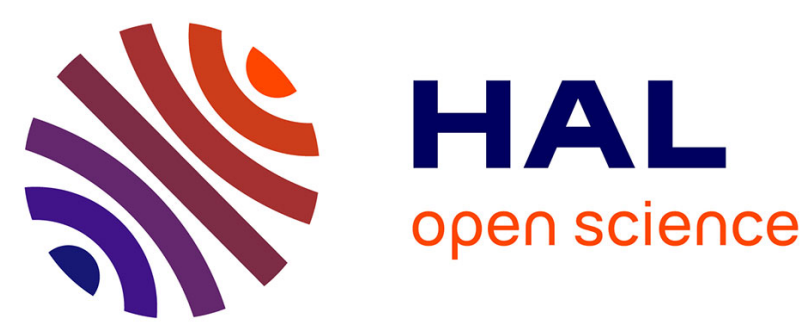

\title{
Road traffic crashes and prescribed methadone and buprenorphine: A french registry-based case-control study
}

Philippe Corsenac, Emmanuel Lagarde, Blandine Gadegbeku, Bernard Delorme, Aurore Tricotel, Anne Castot, Nicholas Moore, Pierre Philip, Bernard Laumon, Ludivine Orriols

\section{To cite this version:}

Philippe Corsenac, Emmanuel Lagarde, Blandine Gadegbeku, Bernard Delorme, Aurore Tricotel, et al.. Road traffic crashes and prescribed methadone and buprenorphine: A french registry-based case-control study. Drug and Alcohol Dependence, 2012, 1 (123), pp. 91-97. 10.1016/j.drugalcdep.2011.10.022 . hal-01027574

\section{HAL Id: hal-01027574 \\ https://hal.science/hal-01027574}

Submitted on 22 Jul 2014

HAL is a multi-disciplinary open access archive for the deposit and dissemination of scientific research documents, whether they are published or not. The documents may come from teaching and research institutions in France or abroad, or from public or private research centers.
L'archive ouverte pluridisciplinaire HAL, est destinée au dépôt et à la diffusion de documents scientifiques de niveau recherche, publiés ou non, émanant des établissements d'enseignement et de recherche français ou étrangers, des laboratoires publics ou privés. 


\section{ROAD TRAFFIC CRASHES AND PRESCRIBED METHADONE}

\section{AND BUPRENORPHINE: A FRENCH REGISTRY-BASED CASE-}

\section{CONTROL STUDY}

Philippe Corsenac ${ }^{1}$, Emmanuel Lagarde ${ }^{1}$, Blandine Gadegbeku ${ }^{2}$, Bernard Delorme ${ }^{3}$, Aurore

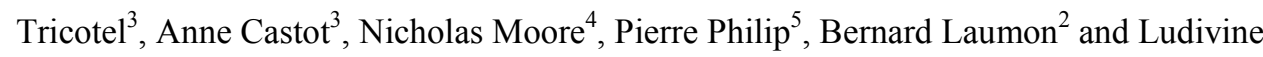
Orriols $^{1}$ on behalf of the CESIR research group

${ }^{1}$ Equipe Prévention et prise en charge des traumatismes, Centre de recherche INSERM U897 "Epidémiologie et Biostatistiques", Institut de Santé Publique d'Epidémiologie et de Développement (ISPED), Université Bordeaux Segalen, Case 11, 146 rue Léo Saignat, 33076 Bordeaux cedex, France

${ }^{2}$ Université de Lyon, Lyon, F-69003, France ; IFSTTAR, Umrestte, UMR T 9405, Bron, F69675

${ }^{3}$ Service de l'évaluation, de la surveillance du risque et de l'information sur le médicament, Agence Française de Sécurité Sanitaire des Produits de Santé (Afssaps), 143-147 Boulevard Anatole France, 93285 Saint-Denis cedex, France

${ }^{4}$ INSERM U657, CIC-P0005, Département de pharmacologie, Université Bordeaux Segalen, Case 36, 146 rue Léo Saignat, 33076 Bordeaux Cedex, France

${ }^{5}$ USR CNRS SANPSY 3413, Université Bordeaux Segalen, 33073 Bordeaux, France

Corresponding author: Ludivine Orriols, ludivine.orriols@isped.u-bordeaux2.fr

Equipe prévention et prise en charge des traumatismes

Centre de recherche INSERM U897 "Epidémiologie et Biostatistiques"

Université Bordeaux Segalen, Case 11, 146 rue Léo Saignat

33076 Bordeaux Cedex, France

Tel/Fax: +(33) 557571504

Word count: 3,489 


\begin{abstract}
Background: Opioids have been shown to impair psychomotor and cognitive functioning in healthy volunteers with no history of opioid abuse. Few or no significant effects have been found in opioid-dependant patients in experimental or driving simulation studies. The risk of road traffic crash among patients under buprenorphine or methadone has not been subject to epidemiological investigation so far. The objective was to investigate the association between the risk of being responsible for a road traffic crash and the use of buprenorphine and methadone.
\end{abstract}

Methods: Data from three French national databases were extracted and matched: the national health care insurance database, police reports, and the national police database of injurious crashes. Case-control analysis comparing responsible versus non responsible drivers was conducted.

Results: 72,685 drivers identified by their national health care number, involved in an injurious crash in France over the July 2005 to May 2008 period. The 196 drivers exposed to buprenorphine or methadone on the day of crash were young, essentially males, with an important co-consumption of other substances (alcohol and benzodiazepines). Injured drivers exposed to buprenorphine or methadone on the day of crash, had an increased risk of being responsible for the crash (odds ratio $(\mathrm{OR})=2.02,95 \%$ confidence interval $(\mathrm{CI})$ : $1.40,2.91)$.

Conclusions: Users of methadone and buprenorphine were at increased risk of being responsible for injurious road traffic crashes. This risk is probably the combined result of risky behaviors and treatments.

Key words: methadone, buprenorphine, road traffic crashes 


\section{INTRODUCTION}

Opioids have been shown to impair psychomotor and cognitive functioning in healthy volunteers with no history of opioid abuse.(Zacny, 1995, 1996) Clinical doses of buprenorphine impair reaction time, muscle coordination, attention and short-term memory (MacDonald et al., 1989; Saarialho-Kere et al., 1987) Likewise, single oral dose of methadone have been shown to increase reaction time and to impair ocular coordination. (Gordon, 1970; Lombardo et al., 1976) Opioids used as a substitution maintenance therapy (buprenorphine and methadone) are prescribed in relatively stable doses over a long period of time (usually more than six months). The effects of long-term use of opioids on driving skills have been reviewed by Fishbain et al in 2003 with little evidence of any association (Fishbain et al., 2003). Available studies were conducted in the 70's in the United States and focused on methadone maintenance (Babst et al., 1973; Blomberg and Preusser, 1974; Maddux et al., 1977). Three more recent studies found no differences in traffic-relevant performances between patients maintained on buprenorphine or methadone and healthy controls. (Baewert et al., 2007; Schindler et al., 2004; Shmygalev et al., 2011) As far as opioids used as analgesics are concerned, the crash risk has been found to be increased by two-fold in two studies using prescription databases (Engeland et al., 2007; Leveille et al., 1994). These results may be partly explained by an irregular use of analgesic opioids as opposed to steady doses for long periods that are prescribed in the treatment of opioid dependence. Other studies used blood and/or urine samples to detect the presence of opioids in drivers involved in a crash.(Drummer et al., 2004; Movig et al., 2004; Mura et al., 2003) Only one of these studies found an association between morphine and the risk of crash $(\mathrm{OR}=8.2,95 \%$ CI: 2.5 27.3).(Mura et al., 2003) These studies are however unable to distinguish between legal and illegal use of opioids. Most of the available epidemiological studies concerned opioids used as analgesics and the few others that focused on substitution maintenance therapy are relatively 
old and limited to the study of methadone effects on the risk of crash. The aim of our study was to investigate the association between the risk of being responsible for a road traffic crash and the use of buprenorphine and methadone within the general driving population.

\section{METHODS}

The study consisted of extracting and matching data from three French nationwide databases. The national health care number (national ID) of drivers involved in injurious crashes was extracted from the police report database. These reports were matched with data from the national police database of injurious crashes to provide details on the crash. National IDs extracted from police reports were sent to the national health care insurance database to collect data on medicine exposure. (Orriols et al., 2010) This study was approved by the French Data Protection Authority.

\section{Crash data}

Police reports. French police forces are required to fill out a police report for each injurious crash defined as a crash resulting in injury for at least one individual involved occurring in the country (about 70000 reports each year). Police reports are scanned and stored as image files. For some of the drivers involved in these injurious road traffic crashes, the national ID is recorded in the police report. This national ID was extracted from image file. All 210,818 available police reports available over the study period (from July 2005 to May 2008) were compiled. The exact number of drivers registered in police reports is unknown as it is not feasible to read manually all police reports. However, this figure may be estimated from the number of drivers registered in the national police database of injurious crashes.

National police database of injurious crashes. Police forces also collect details on the same injurious crash events which are stored in the national police database of injurious crashes. 
This standardized database contains descriptive variables on the crash characteristics, the vehicles and the people involved in the crash. Police forces also conduct additional investigations regarding injury severity from hospital records and categorize the people involved into four groups: unhurt, slightly injured, seriously injured (hospitalized more than 24 hours) or killed (in the 30 days following the crash). All drivers involved in an injurious road traffic crash are supposed to be tested for the presence of alcohol using a breath test. If this test is positive (corresponding to a blood alcohol concentration above the French legal limit of $0.5 \mathrm{~g} / \mathrm{L}$ ), if the driver refuses to take the test or the severity of the crash makes the test impossible, then the blood alcohol concentration is measured. If the breath test is negative then the driver is registered as not being under the influence of alcohol.

National ID extraction and matching procedures. The first step of the study was extracting and matching data from the comprehensive French nationwide databases described above.

Drivers were included through their national ID, gender, and date of birth, as extracted from police reports. An application, based on optical character recognition, was developed to automatically extract, from the image files, the date of the crash, an individual's national ID, gender, and date of birth. The extraction procedure was validated on a subsample of 293 police reports, which were printed and manually coded. A procedure was implemented to match each individual whose ID was extracted from police reports with the corresponding record from the national police database of injurious crashes. Two records were considered matched if six descriptive variables were in agreement. If a pair had three or more discordant variables, it was considered unmatched. For pairs with concordance for fewer than six variables and more than three variables, a probabilistic linkage method was developed (Jaro, 1995). When a decision could not be made automatically, pairs were reviewed by hand. Data on reimbursed medicines dispensed within 6 months before the crash were obtained by linking included drivers to the national health care insurance database using their national ID, 
gender, and date of birth. Confidentiality was ensured by using the personal information anonymization function of the national health care insurance system. (Trouessin and Allaert, 1997)

Medicine exposure data

Health care insurance database. The national health care insurance system database covers the entire French population (in 2008, 64,000,000) and includes data on reimbursed prescription medicines. A record is entered into the database each time a prescription medicine is dispensed to an outpatient at the pharmacy, including the national ID, the date of dispensing and the seven-digit code assigned to the medicine at the time of its marketing authorization. Data on long-term chronic diseases are also registered in this database, with the International Classification of Diseases $10^{\text {th }}$ edition (ICD-10) code, start and end dates of disease.

Exposure periods. Exposure was considered starting on the day following dispensing. To ensure that medicines were not prescribed as a consequence of the crash, medicines dispensed on the crash day were not considered.

Methadone and buprenorphine. French legislation imposes a strict framework for the prescription and dispensation of these medicines (Augé-Caumon et al., 2001). The first prescription of methadone must be filled in by a medical doctor in a specialized care center for drug addicts or in a health care center. Buprenorphine treatment may be initiated in specialized centers but also and mostly in community pharmacies. Methadone is prescribed for no more than 14 days, and on a special form which is non automatically renewable.

Buprenorphine is also prescribed on a specific non automatically renewable form, and for a maximum of 28 days. Usually, pharmacists are allowed to dispense one to seven days' worth 
of treatment with methadone or buprenorphine except if the practitioner mentioned, "to dispense at once”.

The exposure period was estimated from our database as the most frequently observed delay between two dispensations. This delay proved to be seven days for the two medicines, which corresponds to the French legislation.

Concomitant exposure. In France, a four-level risk classification system of medicines affecting driving abilities has been established, ranging from level 0 (no or negligible risk) to level 3 (major risk) (Afssaps, 2009). Comparisons were adjusted for the use of other medicines as classified in the highest levels of risk (levels 2 and 3), including antiepileptics, psycholeptics, all benzodiazepines and derivatives. While the effect of level 2 medicines depends both on phamacodynamics and on individual susceptibility, with level 3 medicines, the pharmacodynamic effect is predominant so all users are advised not to drive. Exposure data was available for all classes of medicines in our database.

Analysis

Subject inclusion. Drivers were censored at their first involvement in a road traffic crash in order to mitigate the impact of previous crashes on medicine exposure. All drivers with a national ID recorded in the police report were included. Subjects whose police reports did not contain their national ID were not included. There are several possible reasons for noninclusion of drivers: the police reports did not contain the driver's national ID (national ID recording is not mandatory), the extraction procedure failed, or the linkage with the corresponding record in the national police database of injurious crashes did not succeed. We compared, by logistic regression, age, gender, injury severity, vehicle type, crash location, type of police forces filling the police report, alcohol level and responsibility between included and non included drivers. 
Descriptive analysis. Frequencies of exposures to methadone or buprenorphine were compared according to individual and crash characteristics. All variables significantly associated with exposure in the bivariate analysis were included in the multivariate analysis, performed by logistic regression.

Responsibility analysis. The purpose of responsibility analysis is to compare exposure probabilities on the day of crash between responsible drivers (cases) and non-responsible drivers (controls). Responsibility levels in the crash were determined by a standardized method adapted from Robertson and Drummer (Robertson and Drummer, 1994). This method, recently validated in France using data from the national police database of fatal crashes (Laumon et al., 2005), takes into consideration the different factors likely to reduce driver responsibility: road, vehicle and driving conditions, type of accident, traffic rule obedience and difficulty of the task involved. A score is assigned to each driver for each of these factors from 1 (favourable to driving) to 4 (not favourable to driving). Drivers were further grouped into two levels of crash responsibility: responsible (score $<15$ ) or nonresponsible (score $\geq 15$ ).

Statistical analyses were conducted using logistic regression. The association between responsibility and age, gender, socioeconomic category, time of crash, season, region of France where the crash occurred (North or South of France), location (urban or non urban), vehicle type, injury severity, blood alcohol concentration (BAC), concomitant treatments (using the four-level French classification system) and chronic long-term disorders were initially investigated using bivariate analysis; these variables were included in the multivariate model as their p-value was less than $20 \%$ (Chi-squared test).

Data were analyzed using the SAS statistical software package, version 9.1 (SAS Institute Inc, Cary, NC, USA). 


\section{RESULTS}

The validation study conducted on 293 police reports showed that the national ID was recorded for 140 of the 455 drivers involved (28\%). The automatic OCR software extracted 110 of these 140 national IDs (extraction rate $=79 \%$ ). Matching with the police national database of injurious crashes was possible for $90 \%$ of the IDs. The driver inclusion rate was thus expected to be around $20 \%$.

Results of the overall extraction and matching procedures are illustrated in Figure 1. We extracted 109,078 national IDs/gender/date of birth, from 210,818 police reports available from July 2005 to May 2008, corresponding to any individual involved in an injurious road traffic crash. Ninety percent of these individuals were matched with a corresponding record in the police national database of injurious crashes $(72.8 \%$ fitted on all variables, $14.0 \%$ were matched by the probabilistic linkage method and 3.1\% manually). The linkage failed for $10 \%$ of the individuals, because the ID corresponded either to a driver involved in the crash but not captured in the police national database or to an individual not involved in the crash (e.g. a witness, the owner of a vehicle involved).

The procedure led to the inclusion of 72,685 drivers ( 34,896 responsible and 37,789 nonresponsible drivers), i.e. $18.5 \%$ of the 392,169 drivers registered in the police national database of injurious crashes.

Injury severity was the main factor associated with the probability of being part of the study (34\% of seriously injured drivers included), thus explaining higher rates of inclusion for bicycle and scooter drivers (27\% and $23 \%$ respectively) and drivers involved in non-urban accidents (25\%), all of whom have been consistently documented in literature to be more seriously injured. The inclusion rate was approximately the same for responsible and nonresponsible drivers (respectively, $18.8 \%$ and $18.3 \%$ ). 
Exposure to buprenorphine or methadone was higher among men and young drivers (29-38 years old) and drivers using level 2 and level 3 medicines. (Table 1$)$ Forty nine drivers (25\% of the 196 buprenorphine or methadone users) were exposed to one or more level 3 medicines and 76 drivers (39\% of the 196 buprenorphine or methadone users) were exposed to one or more level 2 medicines on the day of crash, all belonging to the nervous system class of the WHO Collaborating Center for Drug Statistics Methodology ATC (Anatomical Therapeutic Chemical) classification. These other medicines used concomitantly to buprenorphine and methadone were mainly anxiolytics, hypnotics, antipsychotics and antidepressants. (Table 2)

Adjusted responsibility analysis showed a two-fold increased risk associated with the use of buprenorphine or methadone $(\mathrm{OR}=2.02,95 \% \mathrm{CI}: 1.40-2.91)$. The analysis conducted on the effect of each of these two medicines separately showed an increased risk of being responsible for a crash for buprenorphine users and no significant association was found for methadone users (Table 3).

The same analysis, performed for the 387 drivers who received at least one dispensation of buprenorphine or methadone in the six month preceding their crash, showed an increased responsibility risk for these drivers $(\mathrm{OR}=1.70,95 \% \mathrm{CI}$ : $1.36-2.14)$. The odd ratio was 1.52 , 95\% CI: 1.14-2.03 when excluding the 159 drivers who had a dispensation in the eight days before the crash from the analysis.

\section{DISCUSSION}

72,685 drivers involved in an injurious road traffic crash in France, over a three-year period, were included in the study. We evidenced an increased risk of being responsible for a crash 
among patients under buprenorphine or methadone ( $\mathrm{OR}=2.02,95 \%$ CI: $1.40-2.91)$, as compared to non users. When considering each substance individually, buprenorphine was associated with responsibility risk while there was no association for methadone, probably because of the small number of drivers exposed to this medicine; an effect of methadone can thus not be excluded.

The responsibility analysis is a real strength of the study as it allows for the comparisons of cases and controls that share the same characteristic of being drivers. In a previous study on the impact of illegal drug consumption, using the same police national database but limited to fatal crashes (Laumon et al., 2005), the same method used to determine responsibility was approved by an independent expert evaluation of responsibility. Furthermore, because the responsibility analysis relies on the assumption that non responsible drivers are representative of the driving population, the authors of the previous study validated the comparison of a subset of the non responsible subjects with the driving population in France (Laumon et al., 2005). Finally, the strong dose-effect relationship found in our study between alcohol level and responsibility is a further indirect validation of the method. Importantly, responsibility levels were computed independently of alcohol and illicit drug use because of their potential interactions with medicine use.

A study conducted in 2004, focusing on fatal crashes did not find an association between opiates and driver responsibility. (Drummer et al., 2004) In this study, using toxicological testing, methadone was only one of the tested substances among other licit and illicit opioids making difficult the comparison with our results. Moreover, the authors highlighted the lack of power to address the issue.

The results showed that injury severity was associated with the probability of being part of the study. Thus severely injured drivers were more likely to be included than slightly injured drivers. Killed drivers and uninjured drivers still had lower inclusion rates. This finding can 
be explained by the fact that injured drivers were more likely to be admitted to hospital so their healthcare number was more frequently noted in the police report. Thus, our study sample slightly over-represented drivers injured in more severe crashes.

Medicine exposure was ascertained from computerized records of reimbursed prescriptions filled at the pharmacy. These data were not subject to underreporting, a major problem encountered when medicine exposure data is self-reported (Honkanen et al., 1980). However, we did not know whether the medicines were actually ingested or not. Non-compliance, which we were not able to check, would therefore result in exposure misclassification. Another study showed that the French healthcare insurance data are reliable indicators of actual exposure for medicines used over a long time frame (Noize et al., 2009), which is the case for substitution maintenance treatments.

The first prescription of methadone must be filled in by a medical doctor in a specialized care center for drug addicts or in a health care center. Consequently, our study was unable to consider the very first prescription of methadone. This initiation period might be critical regarding the risk of crash. Buprenorphine treatment may be initiated in specialized centers but also and mostly in community pharmacies. Moreover, some patients will never have any dispensation in community pharmacies and will be only followed in these centers during their whole treatment course. While this loss of information is unlikely to have biased association measures, it has consequences in exposure prevalence estimates which are therefore underestimated.

Prescription of takeaway doses of methadone results in diversion for illicit use by those not in treatment (Mattick et al., 2008) Buprenorphine is even more easily accessible than methadone due to less restrictive policies and some patients may consult several practitioners to acquire more prescriptions (Thirion et al., 2002). Health care insurance data showed that in 2005$2006,25 \%$ of buprenorphine dispensations were for the benefit of $5 \%$ of the patients, leading 
to concern about contraband networks. (Chast, 2009) Misuse and accidents have also been reported (intravenous drug use, fatal overdoses...). (Chast, 2009) While it has been shown that buprenorphine is one of the medicines that are the most frequently reported in suspicious prescriptions (8.8\% of the suspect prescriptions between 2001 and 2004) (Boeuf and LapeyreMestre, 2007), the part of substitution maintenance prescriptions that are diverted from therapeutic remains impossible to estimate.

Codeine is used to reduce withdrawal symptoms or to substitute for other opioid dependence. Because several medicines containing codeine are available without a prescription, these consumptions could not be estimated from the health care insurance database. Néocodion ${ }^{\circledR}$ is a codeine preparation, available without prescription, and also known to be misused by opiate addicts.(Armand et al., 2004; Olivier et al., 2002) A study conducted in 2002 in France estimated that $21 \%$ of Néocodion ${ }^{\circledR}$ users were concomitant methadone or buprenorphine users.(Armand et al., 2004) We observed however that buprenorphine or methadone users had very few concomitantly prescription of opioid analgesic level 2 medicines (as defined in the French classification system) on the day of their crash.

Finally, consumption of illicit products is commonplace in maintained patients. Heroin was reported to be used in $22 \%$ to $59 \%$ of the patients during their treatment. (Amato et al., 2005) Other drugs such as cannabis, cocaine, amphetamines are also frequently reported. In France, the detection of drugs is mandatory in fatal road crashes only and is missing for $95 \%$ of drivers involved in injurious crashes.

In our study, $48 \%$ of the buprenorphine or methadone users were estimated to be exposed to another nervous system medicine on the day of crash; most of these medicines were benzodiazepines and/or benzodiazepine-related medicines. Interestingly, patients were found with very old generation of hypnotics like flunitrazepam which are known to have a strong addictive component. (Sec et al., 2009) A literature review concluded that during substitution 
treatment, about $30 \%$ of patients are affected by dependence on alcohol and benzodiazepines.(Laqueille et al., 2009) Seventeen percent of drivers under buprenorphine or methadone had a blood alcohol concentration above the legal limit as opposed to $5.6 \%$ among other drivers who were not under such treatment. Blood alcohol is however not consistently tested in drivers involved in crashes resulting in slight injury (defined as resulting in a less than 24 hours hospital stay).

In a previous study, using the same database, the odds ratios for prescribed medicines that may have a deleterious effect on driving performances (level 2 and level 3 according to the French classification) were $\mathrm{OR}=1.31,95 \% \mathrm{CI}: 1.24-1.40$ and $\mathrm{OR}=1.25,95 \%$ CI: $1.12-1.40$, respectively. These risk levels mainly include hypnotics, anxiolytics and antidepressants, known to be associated with an increased risk of crash (Barbone et al., 1998; Bramness et al., 2008; Engeland et al., 2007; Gustavsen et al., 2008; Leveille et al., 1994; Neutel, 1995; Neutel, 1998; Orriols et al., 2011; Ray et al., 1992).

It is therefore very unlikely that the OR of 2 found here for buprenorphine and methadone would be solely explained by their pharmacological action. This is an indirect argument in favour of the impact of risky behaviour in this population. A recent study conducted in the same database found a similar risk estimate for drivers with zolpidem misuse (very high consumtion level) $(\mathrm{OR}=2.38,95 \% \mathrm{CI}: 1.61-3.52)$ (Orriols et al., 2011), showing that drivers with a profile of abusers may be more likely to have an increased risk of causing a crash. On the other hand, when considering all drivers who received at least one dispensation of buprenorphine or methadone in the six month preceding their crash, the odds ratio was 1.70 , $95 \%$ CI: 1.36-2.14. When drivers receiving a dispensation in the eight days just before the crash were excluded from this analysis, the odds ratio was even lower $(1.52,95 \% \mathrm{CI}$ : 1.14 2.03). This indicates that an effect of the treatments can not be excluded. A literature review of experimental studies suggested however that there was no impairment of psychomotor 
abilities immediately after the administration of opioids to opioid-maintained patients. This review also showed no impairment of psychomotor abilities as measured in laboratory tests and in driving simulators.(Fishbain et al., 2003) The absence of a relevant impact on driving abilities has also been shown recently in clinical studies (Baewert et al., 2007; Schindler et al., 2004; Shmygalev et al., 2011). However, in such studies, drivers may not behave as in reallife driving conditions. One of the studies underlined the difficulty to generalize the findings due to major problems in this specific patients group (illicit drugs consumption and lack of social reliability) (Shmygalev et al., 2011).

Further work is therefore needed to disentangle the effect of treatments and the characteristics of the particular population using methadone or buprenorphine. 


\section{REFERENCES}

Arrêté du 8 août 2008 pris pour l'application de l'article R. 5121-139 du code de la santé publique et relatif à l'apposition d'un pictogramme sur le conditionnement extérieur de certains médicaments et produits

Castot A, Delorme B and the Working Group "Medicinal products and driving". Medicinal products and driving: how to assess the risk ? P2T Congress Marseille 2009. Abstract ${ }^{\circ} 481$.

Medicinal Products and Driving. On behalf of the Working Group created by Afssaps: Christian Riché, Charles Caulin, Jacques Caron, Anne Chiffoleau, Christian Corbé, Bertrand Diquet, Alain Eschalier, Françoise Haramburu, Georges Lagier, Jean-Pierre Lépine, Michel Mallaret, Charles Mercier-Guyon, Louis Merle, Jean-Louis Montastruc, Pierre Philip, Francis Rodor. http://www.afssaps.fr, section Publications / Information in English.

Observatoire Français des Drogues et des Toxicomanies. Drogues et usages de drogues en France. Etat des lieux et tendances récentes 2007-2009. Neuvième édition du rapport national du dispositif TREND. 2010.

WHO/UNODC/UNAIDS position paper. Substitution maintenance therapy in the management of opioid dependence and HIV/AIDS prevention. 2004.

Afssaps, 2009. Medicinal Products and Driving. Available online at http://www.afssaps.fr/var/afssaps site/storage/original/application/e5f2e48d5344bcfef6ca865 ac63e7c3d.pdf (Accessed 29 August 2011).

Amato, L., Davoli, M., Perucci, C.A., Ferri, M., Faggiano, F., Mattick, R.P., 2005. An overview of systematic reviews of the effectiveness of opiate maintenance therapies: available evidence to inform clinical practice and research. J Subst Abuse Treat 28, 321-329.

Armand, C., Thirion, X., Saillard, C., Lapeyre-Mestre, M., Lambert, H., 2004. [Neocodion misuse: evolution between 1992 and 2002]. Therapie 59, 547-553.

Augé-Caumon, M.J., Bloch-Lainé, J.F., Lowenstein, W., Morel, A., 2001. L'accès à la méthadone en France. Bilan et recommandations: rapport au ministre de la santé. .

Babst, D.U., Newman, S., Gordon, N., Warner, A., 1973. Driving records of methadone maintenance patients in New York State. J Drug Issues 3, 285-292.

Baewert, A., Gombas, W., Schindler, S.D., Peternell-Moelzer, A., Eder, H., Jagsch, R., Fischer, G., 2007. Influence of peak and trough levels of opioid maintenance therapy on driving aptitude. Eur Addict Res 13, 127-135.

Barbone, F., McMahon, A.D., Davey, P.G., Morris, A.D., Reid, I.C., McDevitt, D.G., MacDonald, T.M., 1998. Association of road-traffic accidents with benzodiazepine use. Lancet 352, 1331-1336.

Blomberg, R.D., Preusser, D.F., 1974. Narcotic use and driving behavior. Accid Anal Prev 6, 23-32.

Boeuf, O., Lapeyre-Mestre, M., 2007. Survey of forged prescriptions to investigate risk of psychoactive medications abuse in France: results of OSIAP survey. Drug Saf 30, 265-276.

Bramness, J.G., Skurtveit, S., Neutel, C.I., Morland, J., Engeland, A., 2008. Minor Increase in Risk of Road Traffic Accidents After Prescriptions of Antidepressants: A Study of Population Registry Data in Norway. J Clin Psychiatry, e1-e5.

Chast, F., 2009. [Opiate replacement therapy in France: assessment of the public policies]. Ann Pharm Fr 67, 299-303. 
Drummer, O.H., Gerostamoulos, J., Batziris, H., Chu, M., Caplehorn, J., Robertson, M.D., Swann, P., 2004. The involvement of drugs in drivers of motor vehicles killed in Australian road traffic crashes. Accid Anal Prev 36, 239-248.

Engeland, A., Skurtveit, S., Morland, J., 2007. Risk of road traffic accidents associated with the prescription of drugs: a registry-based cohort study. Ann Epidemiol 17, 597-602.

Fishbain, D.A., Cutler, R.B., Rosomoff, H.L., Rosomoff, R.S., 2003. Are opioiddependent/tolerant patients impaired in driving-related skills? A structured evidence-based review. J Pain Symptom Manage 25, 559-577.

Gordon, N.B., 1970. Reaction-times of methadone treated ex-heroin addicts. Psychopharmacologia 16, 337-344.

Gustavsen, I., Bramness, J.G., Skurtveit, S., Engeland, A., Neutel, I., Morland, J., 2008. Road traffic accident risk related to prescriptions of the hypnotics zopiclone, zolpidem, flunitrazepam and nitrazepam. Sleep Med 9, 818-822.

Honkanen, R., Ertama, L., Linnoila, M., Alha, A., Lukkari, I., Karlsson, M., Kiviluoto, O., Puro, M., 1980. Role of drugs in traffic accidents. Br Med J 281, 1309-1312.

Jaro, M.A., 1995. Probabilistic linkage of large public health data files. Stat Med 14, 491-498. Laqueille, X., Launay, C., Dervaux, A., Kanit, M., 2009. [Abuse of alcohol and benzodiazepine during substitution therapy in heroin addicts: a review of the literature]. Encephale 35, 220-225.

Laumon, B., Gadegbeku, B., Martin, J.L., Biecheler, M.B., 2005. Cannabis intoxication and fatal road crashes in France: population based case-control study. BMJ 331, 1371.

Leveille, S.G., Buchner, D.M., Koepsell, T.D., McCloskey, L.W., Wolf, M.E., Wagner, E.H., 1994. Psychoactive medications and injurious motor vehicle collisions involving older drivers. Epidemiology 5, 591-598.

Lombardo, W.K., Lombardo, B., Goldstein, A., 1976. Cognitive functioning under moderate and low dosage methadone maintenance. Int J Addict 11, 389-401.

MacDonald, F.C., Gough, K.J., Nicoll, R.A., Dow, R.J., 1989. Psychomotor effects of ketorolac in comparison with buprenorphine and diclofenac. Br J Clin Pharmacol 27, 453459.

Maddux, J.F., Williams, T.R., Ziegler, J.A., 1977. Driving records before and during methadone maintenance. Am J Drug Alcohol Abuse 4, 91-100.

Mattick, R.P., Kimber, J., Breen, C., Davoli, M., 2008. Buprenorphine maintenance versus placebo or methadone maintenance for opioid dependence. Cochrane Database Syst Rev, CD002207.

Movig, K.L., Mathijssen, M.P., Nagel, P.H., van Egmond, T., de Gier, J.J., Leufkens, H.G., Egberts, A.C., 2004. Psychoactive substance use and the risk of motor vehicle accidents. Accid Anal Prev 36, 631-636.

Mura, P., Kintz, P., Ludes, B., Gaulier, J.M., Marquet, P., Martin-Dupont, S., Vincent, F., Kaddour, A., Goulle, J.P., Nouveau, J., Moulsma, M., Tilhet-Coartet, S., Pourrat, O., 2003. Comparison of the prevalence of alcohol, cannabis and other drugs between 900 injured drivers and 900 control subjects: results of a French collaborative study. Forensic Sci Int 133, 79-85.

Neutel, C.I., 1995. Risk of traffic accident injury after a prescription for a benzodiazepine. Ann Epidemiol 5, 239-244.

Neutel, I., 1998. Benzodiazepine-related traffic accidents in young and elderly drivers. Hum Psychopharmacol Clin Exp 13, 115-123.

Noize, P., Bazin, F., Dufouil, C., Lechevallier-Michel, N., Ancelin, M.L., Dartigues, J.F., Tzourio, C., Moore, N., Fourrier-Reglat, A., 2009. Comparison of health insurance claims and patient interviews in assessing drug use: data from the Three-City (3C) Study. Pharmacoepidemiol Drug Saf 18, 310-319.

Mis en forme : Français (France)

Mis en forme : Français (France) 
Olivier, P., Maréchal, K., Llau, M.E., Lapeyre-Mestre, M., Damase-Michel, C., Montastruc, J.L., 2002. Use of codeine and non-codeine cough suppressant. A survey among a French network of community pharmacists. Clinical Drug Investigation 22, 399-402.

Orriols, L., Delorme, B., Gadegbeku, B., Tricotel, A., Contrand, B., Laumon, B., Lagarde, E., 2010. On behalf of the CESIR research group. Prescribed medicines and the risk of road traffic crashes: a French registry-based study. Plos Medicine 7, e1000366. doi:1000310.1001371/journal.pmed.1000366.

Orriols, L., Philip, P., Moore, N., Castot, A., Gadegbeku, B., Delorme, B., Mallaret, M., Lagarde, E., 2011. Benzodiazepine-like hypnotics and the associated risk of road traffic accidents. Clin Pharmacol Ther 89, 595-601.

Ray, W.A., Fought, R.L., Decker, M.D., 1992. Psychoactive drugs and the risk of injurious motor vehicle crashes in elderly drivers. Am J Epidemiol 136, 873-883.

Robertson, M.D., Drummer, O.H., 1994. Responsibility analysis: a methodology to study the effects of drugs in driving. Accid Anal Prev 26, 243-247.

Saarialho-Kere, U., Mattila, M.J., Paloheimo, M., Seppala, T., 1987. Psychomotor, respiratory and neuroendocrinological effects of buprenorphine and amitriptyline in healthy volunteers. Eur J Clin Pharmacol 33, 139-146.

Schindler, S.D., Ortner, R., Peternell, A., Eder, H., Opgenoorth, E., Fischer, G., 2004. Maintenance therapy with synthetic opioids and driving aptitude. Eur Addict Res 10, 80-87.

Sec, I., Questel, F., Rey, C., Pourriat, J.L., 2009. [Misuse of psychotropic medications in a population of subjects held for custody in the city of Paris]. Therapie 64, 129-134.

Shmygalev, S., Damm, M., Weckbecker, K., Berghaus, G., Petzke, F., Sabatowski, R., 2011. The impact of long-term maintenance treatment with buprenorphine on complex psychomotor and cognitive function. Drug Alcohol Depend.

Thirion, X., Lapierre, V., Micallef, J., Ronfle, E., Masut, A., Pradel, V., Coudert, C., Mabriez, J.C., Sanmarco, J.L., 2002. Buprenorphine prescription by general practitioners in a French region. Drug Alcohol Depend 65, 197-204.

Trouessin, G., Allaert, F.A., 1997. FOIN: a nominative information occultation function. Stud Health Technol Inform 43 Pt A, 196-200.

Zacny, J.P., 1995. A review of the effects of opioids on psychomotor and cognitive functioning in humans. Experimental and clinical psychopharmacology 3, 432-466.

Zacny, J.P., 1996. Should people taking opioids for medical reasons be allowed to work and drive? Addiction 91, 1581-1584. 
Figure 1. Flowchart of the inclusion procedure.

* The discrepancy between the number of police reports and the number of records in the national police database of injurious crashes is explained by the fact that a small proportion of unavailable reports were being used for on-going further legal investigations.

Table 1. Exposure to buprenorphine or methadone on the crash day according to driver and crash characteristics, France, 2005-2008

Reference group=not exposed to the medicine considered

* The total number of drivers is not equal to 72,685 because of missing values

$\$$ Multivariate analysis, logistic regression, model computed for 61,567 drivers without missing values (2-sided test)

Table 2. Level 2 and 3 medicines used concomitantly on the day of crash, France, 2005-2008

* Some drivers were exposed to several of these medicines

Table 3. Odds ratios for responsible road traffic crashes in users of buprenorphine or methadone, France, 2005-2008

$* \mathrm{p}<0.05, * * \mathrm{p}<0.001$ (2-sided tests)

Reference group $=$ drivers not exposed to the medicines considered

${ }^{\dagger}$ Crude odds ratios

* Model computed for 62,766 drivers without missing values for the adjustment variables

$\S$ Odds ratios adjusted for age, gender, socioeconomic category, region, location, time of day, month, vehicle type, alcohol level, injury severity, concomitant level 2 and 3 medicine exposure and long-term chronic diseases

$\| 2$ drivers were estimated as exposed to both medicines on the day of crash 